\title{
The Use of Persona Based Scenario Method for the Development of Web Board Game for the Pre-elderly
}

\author{
Mi-Ra Seo \\ Department of Game Engineering \\ Tongmyong University, Busan, 608-711, Korea \\ Ae-Kyung Kim \\ Department of Beauty Care \\ Tongmyong University, Busan, 608-711, Korea
}

\begin{abstract}
This study defined the pre-elderly as middle age people from 50 to 59. Because it is difficult to produce a design to satisfy the preelderly without deeply understanding them, their financial and physical characteristics and persona-based scenario method was studied. An experimental study about persona based scenario method was conducted, and as a result, the types of personas found were as follows: 1) Users enjoy the same games online and offline. 2) Users enjoy playing alone on the computer. 3) Users prefer games that end quickly with win or loss. Writing the situation scenario for each type, the pre-elderly's problems and needs occurring while they play web board games were obtained. The obtained user requests were as follows: users would like the level of difficulty to be simpler in the game of baduk; users wanted unlimited credit and refrainment from using English words in go-Stop; and there were simple comments about game screen design.
\end{abstract}

Key words: Web Board Game, Pre-elderly, Persona, Situation Scenario

\section{INTRODUCTION}

Korea, with the expanding lifespan resulting from vast advancement of medical technology and with world's lowest level of birth rate, is expected to have $14.3 \%$ of the population to be elderly in 2018 and $20.8 \%$ in 2026 [1]. Korea will soon mature to an old-age society, therefore requires social and cultural approach to the interest about elderly life. Even with the increase in the elderly group and their use of internet, the research about game users in the game white paper usually investigate users up to the age of 49 . This, as seen in the research focused on users under 49 , means that through the game white paper it is not possible to see information about gaming in the elderly group [2]. Most of the large number of web board games currently in development ignore artistry and user preference, which makes it inapt to buy the interest of the masses. Thus, games for the pre-elderly must be designed based on a systematic and objective analysis of the pre-elderly's use habits and needs. Also, to establish the best design plans, there needs to be cooperation between the user and designers, both with different views and objectives, and there needs to be a communication and decision making method to easily portray

* Corresponding author,Email: yeskak@hanmail.net Manuscript received Dec. 19, 2013; revised Jun. 05, 2014; accepted Jun. 13, 2014 the designer's purpose. On the other hand, due to lack of manpower and financial constraints, a census of the entire preelderly is realistically not possible. Persona based scenario method can be seen as a design method to overcome these limitations.

This study was conducted to explore the possibility of use of the persona based scenario method when developing a web board game for the pre-elderly, and through experimental research, to verify its effectiveness. According to the purpose of research, the research content is largely composed of 2 things. First, there will be a study of the basic concepts and methods to persona based scenario method, then there will be experimental research about the pre-elderly writing persona based scenarios to investigate how the results will be used in the actual development process of web board game development.

\section{UNDERSTANDING OF THE PRE-ELDERLY}

The reason there is no straightforward age standard for the pre-elderly is because the average life expectancy is expanding due to social/ economic development and development of medical technology, and because there is a trend of rising $65+$ population. There is a difference in the age categorization for each researcher due to the fluctuation of age standards by 
culture, age, and status [3]. The age range of the pre-elderly defined in this study is $50-59$, who will be included in the elderly group within 10 20 years [4]

Pre-elderly in the 50-59 age range, with the increase in financial ability, is active in the pursuit of quality of life, and they are at a stage where they are experiencing emotional and physical aging, which means they are a group that is experiencing passion and desire about current life and anxiety about retirement at the same time. Although, this generation is more financially stable compared to the other elderly generations, with the periodical check ups and ample nutrition although there is decrease in biological ability- there are no big differences in the physical side. Looking specifically at the cognitive and physical characteristics of the pre-elderly; first there is the increase in required time for accurate physical action, memory recall, and information processing ability. Also, there is the characteristics of decrease of ability to receive simultaneous momentary information, decrease in the ability to focus in length, and decrease in the amount of information and content that can be obtained from displays related to memory and education [5]. Generally the young elderly, due to the physical constraints listed above, participate more in passive leisure activities rather than active leisure activities, and because social/ cultural leisure activities have to be thought with the approachability of cost and place in mind, there is rather a low rate of participation [6]. Thus it is important to find a leisure activity that has low physical and financial burden that they can actively participate in, then to have the pre-elderly participate in it. A leisure activity that can satisfy these conditions are computer internet games. The advantage is that in an indoor setting, with relatively low physical burden, one can use his/her physical and cognitive ability to actively participate in a leisure activity [7].

According to the game user survey report in 2013 by the Korea Creative Content Agency, the percentage of the group in their 50 's that use internet for leisure was $71.6 \%$, and in their 60 's, $40.8 \%$. In the analysis of the internet usage statistics from 2010 , there was a rise from $55.2 \%$ to $57.4 \%$ in the 50 's age group, and $21.8 \%$ to $22.9 \%$ in the 60 's group [8]. Although online activity using internet and digital devices by elderly groups is rapidly increasing, the games aimed at the pre-elderly are usually about giving special purpose such as education, training, and treatment in a game form, and there is a lack of development of diverse genres of games [9]-[11].

\section{PERSONA BASED SCENARIO METHOD}

Persona is defined as hypothetical people that represent various types within the target group that will use the products or services [12], and in the factors that make up the persona include user profile, users' digital device use ability, user tendencies, and user needs. Persona method enables the discovery of factors that can be missed by statistics such as using user surveys, and extraction of user characteristics pattern, which makes it a very useful method of understanding the users [13]. On the other hand persona, in the process of recreating users, is not limited to personifying users. Based on the conditions that users have, it makes prediction possible by giving feasibility in feature selection. Because of these reasons, persona based scenario method is often distorted in the understanding that it is a method that establishes a fictional character [14].

The characteristics of persona based scenario method that well explains how users achieve their tasks by comprehensively describing the users, environments, task objective, usage, and events are; first, it is hypothetical. Because the future is the future where one cannot predict, studies about the future is about exploring the possible future and designing future scenarios. Second, scenario is not limited to simple descriptions or outlines. As in movies scenarios represent a short plot about simple descriptions or actions of the main characteristics, scenarios describe in detail the status of the major turning point in the future. Thus, in the development of scenarios, choice plays the most important role [15].

In terms of design as well, persona based scenario method is a description of the work situation, the tasks that the user must perform, and tasks that the user wants to perform; it is defined as drawing the future technology that will help users do what they want to do. Also, based on the overall environment of the user's actual work, hypothetical stories that describe user resources and task objectives can take the role of showing how technology and humans interact to suggest guidelines for design [16].

\section{CASE STUDY}

\subsection{Experiment target selection and survey method}

This interview set the experiment target as male and female within 50 59 years of age that had experience in online games. For the 1:1 interview, the researcher and coresearcher visited a welfare center and senior college to explain clearly the experimental purpose and objectives to the 47 users, then conducted the 1:1 interview. Especially in the 50's interview takers, the age range characteristics and lifestyle was considered, and the face-to-face interviews were conducted at a beauty related shop. An in-depth approach to the pre-elderly's need is analyzed through this. The main content of the 1:1 interview was the pre-elderly's general information, offline board game experience, purpose of using games, and questions about habits as well such as internet and game use times, game play times etc.

\subsection{Result of Analysis}

Table 1. Gender and age range cross table of the interview participants

\begin{tabular}{|c|c|c|c|c|}
\hline \multirow{2}{*}{\multicolumn{2}{|c|}{ Category }} & \multicolumn{2}{|c|}{ Age range } & \multirow{3}{*}{$\begin{array}{c}\text { Total } \\
12\end{array}$} \\
\hline & & \multirow{2}{*}{$\begin{array}{c}50 \sim 54 \\
8\end{array}$} & \multirow{2}{*}{$\begin{array}{c}55 \sim 59 \\
4\end{array}$} & \\
\hline \multirow{4}{*}{ Gender } & Male & & & \\
\hline & Total(\%) & $17 \%$ & $8.5 \%$ & $25.5 \%$ \\
\hline & Female & 24 & 11 & 35 \\
\hline & Total $(\%)$ & $51.1 \%$ & $23.4 \%$ & $74.5 \%$ \\
\hline \multicolumn{2}{|c|}{ Total } & 32 & 15 & 47 \\
\hline \multicolumn{2}{|c|}{ Total(\%) } & $68.1 \%$ & $31.9 \%$ & $100 \%$ \\
\hline
\end{tabular}


It could be seen that the interview participants were mostly women with the ratio of genders being men $25.5 \%$ (12) and women $74.5 \%$ (35). Also looking at the age range, it was observed that 32 of the participants which is $68.1 \%$, were between 50 and 54 , and 15 of the participants which is $31.9 \%$ were 55 to 59 . There was a large ratio of women in their early 50 's.

In the result of the interviews, the types of personas found were as such: 1) User that enjoys the same games on and offline. 2) User that enjoys playing alone on the computer. 3) User that prefers games game that ends quickly with win or loss. There were no significant differences in the number of people in each type, but the largest group was the users that enjoy the same games on and offline with 17 people.

Table 2. Persona types \& major characteristics

\begin{tabular}{l|l|c}
\hline \multicolumn{1}{c|}{ Type } & \multicolumn{1}{c|}{ Major characteristics } & $\begin{array}{c}\text { No. of } \\
\text { People }\end{array}$ \\
\hline $\begin{array}{l}\text { Type 1. User that } \\
\text { enjoys the same } \\
\text { games on and } \\
\text { offline }\end{array}$ & $\begin{array}{l}\text { Users that enjoy games that } \\
\text { have same on and offline } \\
\text { formats such as golf, pool, go- } \\
\text { stop, chess, and baduk }\end{array}$ & 17 \\
\hline $\begin{array}{l}\text { Type 2. User that } \\
\text { enjoys playing } \\
\text { alone on the } \\
\text { computer }\end{array}$ & $\begin{array}{l}\text { User that usually uses } \\
\text { personal computer at home } \\
\text { alone to play games around } \\
\text { dinnertime to pass free time }\end{array}$ & 15 \\
\hline $\begin{array}{l}\text { Type 3. User that } \\
\text { prefers games game } \\
\text { that ends quickly } \\
\text { with win or loss }\end{array}$ & $\begin{array}{l}\text { User that, within the various } \\
\text { game genres, likes games that } \\
\text { end quickly with win or loss }\end{array}$ & 15 \\
\hline
\end{tabular}

\subsection{Scenario modelling}

Because persona development can be rather limited to describing the personality and characteristics of the persona [13], in this study, 3 user types seen above were developed based on the pre-elderly's online game main behavior patterns and characteristics. The main personas were derived and situation scenarios were written so that more pre-elderly people could easily learn and use online games.

The situation scenario was written based on the situations that the pre-elderly experience before and after logging on and enjoying online games. Through chronological method the timeline up to the playing of the online game was imagined by hour and it was a system where things that could happen before game play and what is needed during game play was imagined freely.

Table 3. Persona based scenario modelling for the user that enjoys the same games on and offline (Type 1)

\begin{tabular}{l|l}
\hline \multicolumn{2}{c}{ Persona Derivation } \\
\hline User Profile & $\begin{array}{l}\text { Name : Kim Sangsoo } \\
\text { Age : } 55 \\
\text { Occupation : Self-employed (real estate } \\
\text { agent) after retirement } \\
\text { Family status : Spouse, 1 son 1 daughter }\end{array}$ \\
\hline
\end{tabular}

\begin{tabular}{c|l}
\hline $\begin{array}{c}\text { User's digital } \\
\text { device use } \\
\text { ability }\end{array}$ & $\begin{array}{l}\text { Devices used : computer, cell phone, digital } \\
\text { camera } \\
\text { Computer use ability : inexperienced in } \\
\text { information research and utilization, uses } \\
\text { computer exclusively for baduk }\end{array}$ \\
\hline \multirow{3}{*}{ User tendency } & $\begin{array}{l}\text { Prefers being in groups rather than being } \\
\text { alone } \\
\text {-Many friend gatherings that he hosts }\end{array}$ \\
\hline
\end{tabular}

Because there was not many chances of using the computer at work before retirement, there is a feeling of pressure using the computer. Because of this he attends the free computer class at the welfare center every morning for 2 hours. Although it has been a while since he started real estate business, because of his personality that likes meeting new people, every day he delays going to work in the morning to play baduk for a few hours every morning at the welfare center. Because he is interested in baduk and from hearing about it around him, he logged into the Naver Hangame baduk with the help of the computer teacher, but because it was too fast and the way of progress was different from offline baduk, he is repeatedly going on and off of the games. At work he only uses the computer for real-estate related work such as construction register and land register. With the office computer, because one can watch people play online without participating in it, he keeps it on. When there are no customers, he enjoysplaying a game of baduk. Because he goes home late since he opened up a real estate office and cannot meet friends as often, he usually enjoys games in the daytime.

Table 4. Persona based scenario modelling for the user that enjoys playing alone on the computer (Type 2)

\begin{tabular}{|c|c|}
\hline & Persona Derivation \\
\hline User Profile & $\begin{array}{l}\cdot \text { Name : Park Yeonhee } \\
\cdot \text { Age : } 59 \\
\cdot \text {-Occupation : Housewife } \\
\text { ·Family status : Widowed, } 2 \text { sons } 1 \text { daughter }\end{array}$ \\
\hline $\begin{array}{l}\text { User's digital } \\
\text { device use } \\
\text { ability }\end{array}$ & $\begin{array}{l}\text {-Devices used : computer, cell phone, digital } \\
\text { camera, navigation } \\
\text {-Computer use ability : inexperienced in } \\
\text { information research and utilization, but has } \\
\text { high interest in games, at a level where she is } \\
\text { not uncomfortable with game play }\end{array}$ \\
\hline User tendency & $\begin{array}{l}\text { - Likes travelling and watching movies with } \\
\text { friends. } \\
\text { ·Has high interest in things that younger } \\
\text { generations do and has a new-age tendency } \\
\text { of wanting to learn everything. }\end{array}$ \\
\hline
\end{tabular}




\section{Situation Scenario}

At 8am, before her daughter goes to work, she heads to her daughter's apartment which is the complex beside hers. Instead of her busy daughter preparing for work, she makes breakfast for her grandson and takes him to the kindergarten. After she take him to the kindergarten, she visits the sauna at the community center within the apartment complex to pass time with her friends in her age range. She eats a simple lunch at her home and plays go-stop for about an hour before her grandson needs to be picked up from the kindergarten. After making a snack for her grandson, she spends time with him until $7 \mathrm{pm}$ when she heads home. As she is widowed, she has a lonely dinner by herself with the TV on as comfort. When the TV drama ends, she changes to her reading glasses for the computer, turns on the computer and enjoys about 2 hours of games each day. She is bound by her grandson's kindergarten pick up schedule during the week so she talks with others by chat and enjoys go-stop. Because of her chronic rheumatoid finger arthritis there is a limitation that she cannot play games for more than 2 hours, and she finishes every time with a bit of dissatisfaction, but in reality, there are more cases where she has to finish because she ran out of game money. She plays in the same manner in the same order every day but when like today the main screen of the game is upgraded or English type expression appears, she wanders in confusion, then calls her daughter for help.

Table 5. Persona based scenario modelling for the user that prefers games game that ends quickly with win or loss (Type 3)

\begin{tabular}{|c|c|}
\hline \multicolumn{2}{|r|}{ Persona Derivation } \\
\hline User Profile & $\begin{array}{l}\cdot \text { Name : Hwang Miseon } \\
\cdot \text { Age }: 51 \\
\cdot \text { Occupation : Teacher } \\
\cdot \text { Family status : Spouse, } 2 \text { sons }\end{array}$ \\
\hline $\begin{array}{l}\text { User's digital } \\
\text { device use } \\
\text { ability }\end{array}$ & $\begin{array}{l}\text { - Devices used : computer, cell phone, digital } \\
\text { camera, scanner, projector } \\
\text {-Computer use ability : Very experienced in } \\
\text { information research and utilization, can } \\
\text { create educational digital content (lessons) by } \\
\text { herself. }\end{array}$ \\
\hline User tendency & $\begin{array}{l}\text {-A type that likes quiet time by herself } \\
\text {-Style where she does not postpone and } \\
\text { always prepare and plan in advance }\end{array}$ \\
\hline
\end{tabular}

Because she lives in a house the suburbs she leaves home early every day to go to work. Considering traffic when going to work, there are many times she arrives at work earlier than necessary. Today she also arrived early and she ventilates the classroom, then turns on the computer at her desk to play minesweeper.

She passes about 20 minutes with the game drinking coffee and ends the game when the students start to arrive. Although she has no time during the morning and afternoon classes, because she always packs a natural food based lunch, she has more time than most others at lunchtime. Although short, in this time she enjoys personal games. Because minesweeper has a short play time she can always finish when she want to so she uses it often. However she does feel a bit fed up with the old design year after year. Although the play time is short, the problem is that she sometimes plays until the sun rises because she cannot get herself to sleep. Although the match is finished in short time, because of the addictiveness she tries not to play games in the evening.

\section{CONCLUSION}

Before the main experimental study, the study about the pre-elderly's financial and physical characteristics and literature study about persona based scenario method was conducted. In the result of the study, the age range of the pre-elderly is 50 to 59 , and they will be within the elderly group in 10 to 20 years time. The main characteristic of this group is that compared to the existing elderly group, they are financially stable and has a relatively high participation rate in self-improvement and social activities. In terms of physical health, with the periodical check ups and ample nutrition-although there is decrease in biological ability- there are no big differences in the physical side. Through writing in narrative the flow of time from the point where the pre-elderly start web board games to when they are using the game, and including the expected problems that arise, it was determined that the method that could derive the needs when developing a game for the target users of web board games was persona based scenario method.

In the experimental study analysis of the study subjects, the personas of the pre-elderly is divided into 3 types. First there are users that enjoy games that have same on and offline formats such as golf, pool, go-stop, chess, and baduk which is a 'type of user that enjoys the same games on and offline.' Second there are users that usually use personal computer at home alone to play games around dinnertime to pass free time which is a 'type of user that enjoys playing alone on the computer.' Lastly, there are users that, within the various game genres, like games that end quickly with win or loss which is a 'type of user that prefers games game that ends quickly with win or loss.' In the 3 types, it was observed that there were more pre-elderly users that enjoy games that have same on and offline more than the other types. On the other hand, writing the situation scenario for each type, the pre-elderly's problems and needs that occur when they play web board games was obtained. The obtained user requests were: that they would like the level difficulty of baduk to be simpler, that they wanted unlimited credit and refrainment of use of English words in go-stop, and there were simple comments about game screen design where they expressed that the game design did not satisfy the user.

Therefore the significance in this study is that based on the various user experiences and characteristics of pre-elderly that use web board games, personas were created and applied. Thus, the value is in that the representative personas that are key factors derived from the user experience and behavior were created and applied and that systematic insight useful in web board game development for games that are easy to understand 
and use such as user needs, service planning, and design direction was obtained.

\section{REFERENCES}

[1] A. K. Kim and M. R. Seo, "Sociodemographic Characteristics of Korean elderly people through game user survey," The 3rd International Conference on Convergence Technology 2013, 2013, pp. 1627-1628.

[2] M. R. Seo and A. K. Kim, "Deduction of persona through online game playing behaviors analysis of young elderly people," The 3rd International Conference on Convergence Technology 2013, 2013, pp. 1625-1626.

[3] B. R. Jang, A Study on Young-Old People's Patterns of Consuming Art and Culture by Lifestyles, Sookmyung University, 2009.

[4] C. S. Cho, A study on housing preference for the old age according to the lifestyle of the preliminary elderly, Pusan National University, 2010.

[5] H. J. Lee, H. Y. Chu, S. E. Oh, N. K. Kim, H. M. Kim, S. M. Yang, and S. J. Chung, "A Study of Emotional Color Communication for New Silver Generation," Journal of Korea Society of Design Science, vol. 24, no. 2, 2011, pp. 287-298.

[6] J. S. Hur, "Determinants of Leisure Activities among Urban Elderly Persons," Journal of the Korea Gerontological Society, vol. 22, no. 2, 2002, pp. 227-247.

[7] J. H. Ahn, K. C. Lim, Y. J. Lee, and K. S. Kim, "Effects of Computer/Internet Game Play on Depression and Life Satisfaction among the Elderly: Mediating Effects of Perceived Self-Control," Journal of the Korea Contents Association, vol.11, no.7, 2011, pp. 406-417.

[8] Korea Creative Content Agency, "A Report of Game User Survey in 2013," Korea Creative Content Agency, 2013.

[9] K. S. Yoo, W. I. Kim, H. J. Youn, D. J. Lee, and W. H. Lee, "A Design of Functional Game Contents and Analysis of Power Spectrum," Journal of Korea Game Society(JKGS), vol. 6, 2005, pp. 1-7.

[10] E. S. Kim, H. C. Lee, J. H. Joo, and G. T. Hur, "Developing Functional Game Contents for the Silver Generation," Journal of the Korea Contents Association, vol. 9, no. 9, 2009, pp. 151-162.

[11] E. S. Kim, H. C. Lee, and B. S. Kim, "A Method of Functional Game Design for the Silver Generation," Journal of Korea Multimedia Society(JKMS), vol. 13, no. 1, 2010, pp. 143-152.

[12] K. M. Song, "Wayfinding Planning in Public Space Useing Persona-based Scenario Method," Journal of Urban Design, vol. 10, no. 1, 2009, pp. 21-34.

[13] H. J. Lee, Y. M. Kim, J. H. Park, D. M. Kim, and H. Y. Ryo, "Investigating User Activities \& Generating Personas for U-zone Development," Journal of Digital Design, vol. 7, no. 4, 2007, pp. 81-90.

[14] H. M. Seo, Scenario Method based on Persona for mobile User eXperience: UX, Sungkyunkwan University, Korea, 2013.
[15] D. J. Noh, “A Study on the Forecasting of Library Service with Scenarios," Journal of Korea Library and Information Science Society, vol. 35, no. 4, 2004, pp. 361-375.

[16] H. L. Kim and S. H. Park, "Studies of User Interface Design by Scenario in Driving-Case Studies Focused on the Digital instrument Cluster System in an Intelligent Vehicle," Journal of Society of Design Convergence, no. 7, 2005, pp. 37-48.

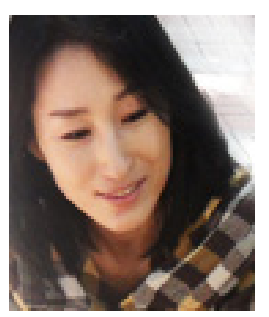

\section{Mi-Ra Seo}

She received her B.A. degree in Industrial Design from Chonbuk National University, Korea in 1994, and M.A. in Multimedia Design from De Montfort University, England in 1998, and also received Ph.D. degree in Image Engineering from Chonbuk National University, Korea in 2007. Since then, she has been with Tongmyong University, Korea as a professor. Her main research interests are Digital Contents, Interface Design, Game graphic.

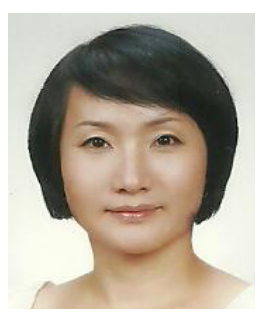

\section{Ae-Kyung Kim}

She received the B.S., degree in Clothing \& Textile from Dong-a University, Korea in 1986, and M.A. Ph.D in Clothing \& Textile from Pusan National University, Korea in 2003, 2010 respectively. Since then, she has been with Tongmyong University, Korea as a professor. Her main research interests are Color Design, Color Psychology. 